\title{
Analysis of EFL Teaching in Pakistan: Method and Strategies in the Post- method Era
}

\author{
Muhammad Asif Ali Khan \\ Ontario Institute for Studies in Education, Toronto, Canada \\ raoasifjah@gmail.com
}

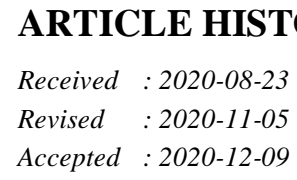

\section{KEYWORDS}

English as a Foreign Language Teaching Method

Teaching Strategies

\begin{abstract}
This study investigates the teaching methods and strategies practised in Pakistan to teach English as a foreign language in the Post-method Era. English language pedagogy in Pakistan has taken a new turn since the establishment of higher education commission and applied linguistic departments in many universities in Pakistan. It focuses on classroom teaching analysis to see what teaching methods and strategies that English language educators in private and public institutes apply. The study applied qualitative methods with five English teachers as Foreign Language (EFL) of the public and private sectors' intermediate level. The participating teachers were given nine open-ended survey questions about the nature of language, language teaching methods, classroom strategies and techniques, and their roles as teachers in the classroom. Findings revealed that EFL teachers in both public and private sectors employ multiple teaching methods and techniques in their classroom practice, rather than holding to one particular method. The data also differentiates teaching methods and strategies of the teachers in the both sectors. Interestingly, it appears that EFL teachers in the private sectors seem to aim at communicative teaching approaches. In contrast, teachers in the public sectors are more inclined to use Grammar Translation Methods (GTM).
\end{abstract}

\section{Introduction}

In Pakistan, the English language holds the official language and medium of instruction, particularly in the private and higher education sectors. It is used as a medium of communication in government institutes and business organisations across Pakistan. However, EFL teachers can lack formal training, and there is a lack of consistency in the use of course books and audio-visual aids. Teachers, whether or not they are aware of it, use different strategies from classroom to classroom. As a result, the standard method and strategies of ELT in Pakistan are considered unsatisfactory (Teevno, 2017, p.2).

As all agree, English is now considered global lingua franca, and a person who possesses remarkable skills in communicating in English avails better opportunities in career and professional life. In contrast to the one who lacks such proficiencies in English; the same privilege a well-versed English speaker in Pakistan enjoys. However, our educational institutes and language learning centres across Pakistan differ in their ELT methods and strategies. As a result, a noticeable number of ESL students fail to achieve English essential skills (Hussain, 2017). It is the medium of instruction in all higher educational institutes that means teachers deliver their lectures and English subjects' lectures; students attempt their English exams. In practice, teachers encourage students to discuss the topic in English.
Across Pakistan, the primary sources of English language learning are the private language centres, where the emphasis is on memorising spellings, translation, and understanding grammar rules. For instance, at these centres, teachers provide their students with a list of words and phrases to memorise; secondly, students learn the everyday expressions and use of language through translation. More importantly, the stiff and rigid rules of grammar are explained with code-switching and in comparison, with the students' first language. Hence, the need to teach English with the situated use is eminent (Khan, 2016). As a result of these old and traditional ESL methods, a visible majority of students lose their motivation and discontinue their course (Hussain, 2017). Because of the decontextualized ESL teaching, students fail to make fair use of their language learning in their daily lives. On any day in Pakistani life, find more occasions to speak in English instead of writing. Regardless, cognitive skills play a similar role in oral communication and writing (Asghar \& But, 2018).

Pakistan, like Indian, is another multilingual country with over 70 languages and variations. The national language is Urdu, and four local languages (e.g., Sindhi, Punjabi, Pushtu, and Balochi) also enjoy special attention in the educational system in their respective provinces. Regardless of all these local languages, English is the only second language learned and taught across the country. It is also taught 
as a compulsory subject from grade 1 to undergraduate in Pakistan. There is an eminent global demand for English speakers in Pakistan that the traditional system of GTM has failed to produce (Ahmed \& Rao, 2013). As a result, there is a recent discussion and mandate for teaching English from the applied linguistic viewpoint (Jailani, 2004, p.8).

The course description in the syllabus does not offer much help to language teachers to develop essential English skills, and preferably, the text implies memorisation. Students in class read the text loud but fail to comprehend it. Similarly, this ELT tradition does not improve students' writing skills. Most students' writing skills are also relatively low, and they cannot write a complete well-structured sentence.

Therefore, this study explores the teaching methods and strategies qualitatively applied by EFL teachers at the intermediate level in Pakistan's public and private sectors. Freeman (2000) states that "when teachers are exposed to methods and asked to reflect on their principles and actively engage with their techniques, they can become more transparent about why they do what they do. They become aware of their fundamental assumptions, values, and beliefs (p.ix)."

The study investigates if teachers are still strictly using one prescriptive method or using their freedom to adjust techniques and strategies to develop L2 skills and proficiency. This study also sheds light on how EFL teachers in Pakistan view the nature of language and language learning, the role they play in the classroom, the socio-culture relevant pedagogies they applied. The data were collected from ELT teachers from both in the public sector or private sector post-secondary colleges of Pakistan. This study's area is limited to the teaching method, methodologies, strategies, and classroom techniques used by the participating teachers to develop either accuracy or proficiency in L2.

\section{Literature Review: The Post-method Era}

Since the establishment of the higher education commission in 2005 and applied linguistic department in many universities, several rigorous research types have been conducted in English language pedagogy. Khan and Akhter (2017) suggest the way to improve the standard of English language in Pakistan by advocating the "explicit knowledge of grammar" (p.2) for second language learning. On the other hand, Jamil (2014) signifies the "critical understanding of the working of language", (p.1) for precise and purposeful communication. The confusion of form and function of the English language is still the core issue in Pakistan as in academic level accuracy in the English language is valued. At non-governmental business sectors, meaningful communication is highly appreciated. The condition of EFL in Pakistan is not entirely satisfactory, especially in rural areas. Most English language teaching programs lack adequate language education goals, design, and methodology. Ghulamullah (2017) stresses learners' skills acquisition and maintains that a clear presentation of the L2 curriculum would benefit both teachers and L2 learners.

Despite all, the business of language teaching is progressing at a fast pace. Muhammad, Natasha \& Shumaila (2016) investigated the pedagogical techniques in teaching and learning EFL and found that many teachers in the public sector faced problems of exercising new techniques from the centre in their classroom with students from various linguistic and cultural backgrounds. They also found that many teachers were unwilling to adopt innovative teaching methods; thus, these teachers fail to create a productive learning environment.

The overemphasis on form rather than a function of the English language is based on the fact the English language is the medium of examination and instruction in higher education in Pakistan; it is also the medium of official communication in writing in government documentation. Hence, many publicsector universities in Pakistan now offer English courses, including English for the Academic Purpose (EAP) and remedial grammar courses. Many official bodies, such as the Punjab Education and English Language Initiative (PEELI), the British Council in Pakistan, the Pakistan English Language Teachers Association (PELTA), and The Society of Pakistan English Language Teachers (SPELT) have attempted to address the various issues related with EFL and L2 pedagogy over the years but the benchmark of communicative competence is still very low. The reason for this may be that new English teachers lack access to professional language teaching programs.

The dominant method in the public sector is that language is a phonemes system, structure, and syntax. Thus, Grammar Translation Method (GTM) is prescribed and practised to improve the accuracy of L2 learning (Ghulamullah, 2017; Gulzar \& Sultana, 2009). By way of contrast, in the private sector, teachers are less dependent on the GrammarTranslation method. Instead, they employ a communicative approach by focusing on the function instead of the form of the target language. It is popular as a marketing strategy for their language centres in the private sector, so most teachers shun the GTM and prefer to use the CLT approach (Warsi, 2004; Gulzar \& Sultana, 2009).

English language teaching includes global perspectives with a wide range of teaching methods and strategies being applied by language educators worldwide. These teaching methods differ in their context, learner's need, styles, and preferences. Widely known scholar Kumaravadivelu (2006) claims the methods are dead, and we are in the post-method 
era where one prescriptive method may not fit all learner's needs and culture (Kumaravadivelu, 2006). He believes that language educators cannot be trained to use a single method that may not have universal application (Kumaravadivelu, 2006). In his book, he insists language teachers "go beyond the limited, and limiting, the concept of method and consider the challenges and opportunities of an emerging postmethod era in language teaching' (Kumaravadivelu, 2006, p.2). The disappearance of the method has given rise to the post-method debate (Akbari, 2008).

The post-method pedagogy suggested by Kumaravdivelau appears to provide a pedagogical explanation for teachers' problems of the second language across the globe. Indeed, he revolutionises the very concept of the Method of L2 teaching. Kumaravadivelu (2003) urges teachers to go beyond any prescriptive pedagogical methods and employ to post-methodological pedagogy. His post-method pedagogy gives practising teacher freedom to construct personal theories based on their practices and context. Additionally, it signifies teacher autonomy, and unlike eclecticism, post-method pedagogy stresses principled pragmatism, (Kumaravadivelu, 2006).

Scholarly discussion of the Post-method gives the impression that each L2 educator can shape their context-sensitive practice according to relevant theories. However, the question remains unclear as to whether teachers must undergo special training to develop learning material and design their test without relying on language learning. Most coursebooks are based on a particular method, which is marketed and promoted.

Secondly, most teachers are aware of some burning issues related to society's social and political problems. Even a light conversation on such issues may put the teacher in some serious situation. For example, in Arab Saudi and China, language educators are not supposed to discuss social and political problems in the classroom. Hence, the part of the post-method pedagogy that puts a teacher in a transformative intellectual role as an agent of change remains impossible. Most importantly, language teachers' recruitment agency always presents the requirement and responsibilities that $\mathrm{L} 2$ teachers are supposed to perform; these requirements do not include teacher role as agents of change. If the postmethod is a movement that turns away from the prescriptive method and regards method as dead, their evidence and data should have included teachers' views about their role worldwide.

\section{Method}

The primary source of data collection was the EFL teachers in the public and private sectors. The reason for selection is that these teachers teach in various Pakistan cities, including Lahore, Karachi, Hyderabad,
Dadu, and Peshawar, hence their location covers the different region with particular communities and culture. Additionally, these are major urban centres with higher educational institutes serving both urban and rural students. All the participants teach English at the post-secondary level, which focuses on adultESL learners from various regions of the country.

Does the L1 of learners and the language learning institute's region also play any role in designing teaching methodologies? These learners' first language differs from other regions; for example, ESL learners from Lahore speak Punjabi as their first language while learners in Dadu speak Sindhi. In Peshawar, the first language is Pushto. Furthermore, in Karachi and Hyderabad majority of learners use Urdu as their first language. Therefore, these were teachers selected to determine their learners' first language and the region impacts on their teaching strategies and techniques.

\subsection{Data Collection}

For this study, five teachers participated. They were sent via email the Google form with nine openended questions covering the area of language teaching method, strategies, factors influencing their choice of strategies, coursebook, and their role in the classroom.

The instrument for data collection was mainly the Google form. After, the qualitative survey data were categorised into themes related to ELT methods and strategies in the light of the post-method era. After that, the data were analysed descriptively and comparatively within the themes of the post-method era. The conclusion was built on the after describing, and comparing the participating teachers' responses from both the public and private sectors.

\subsection{Procedure}

This study was conducted on the following nine open-ended questions with 5 participant teachers of English in public and private sectors in Pakistan:

a) What teaching methods/approaches do you use to teach English as a foreign language? What types of activities, do you conduct, do you integrate all our skills or teach them separately?

b) How effective is the Communicative Language Teaching in your classroom? Does L1 play any role in developing L2 in your class? Give us some background of the socio-culture language need and wants of your students?

c) What is a language to you (is the language a system of discrete grammar items or is the language a way of expressing meaning and ideas), and what does it mean to know and use a language (is to know a language to mastering the discrete grammar items or developing ability to communicate in the target language)? (answer it 
was keeping in mind the local context and your students' need, wants and style of learning L2).

d) There is no best method, but it is a post-method era. Which of the following methods are very common in your classroom, based on your experience, kindly brief why?

1) Grammar Translation Method

2) Direct Method

3) Audio-Lingual Method

4) Communicative Language Method

5) Structural Approach

6) Task-based language learning

7) The Natural Approach

8) Total Physical Response (TPR)

9) Suggestopedia

e) Which coursebook are you using and how practical is the coursebook in developing English language proficiency and accuracy? Do you also use some supplementary materials for developing L2; do you keep the form, function, or context of the language system in mind for selecting the supplementary materials?

f) In teaching English, do you also consider developing the target language's cultural competence, or do you regard English as the language of globalisation with zero cultural competence of English-speaking societies? Tell us why?

g) There are many reasons why a particular lesson plan, material, approach, method work well in one context but not in another context. How do you manage, frame your pedagogic strategies to develop L2, or which of the following context do you consider in mind in developing your teaching strategies and techniques?

h) According to Kumaravadivelu (2006), "Teacher must be enabled to develop the knowledge, skills attitude and autonomy necessary to construct their context-sensitive theory of practice,". Do you rigidly follow the theories of language teaching and methods developed by the western thinkers and theorists or develop your theories of practice?

i) Do you encompass your teaching the social, political, and cultural realities, and do you play a transformative role in creating awareness of social, political, and cultural realities among your learners?

\section{Findings}

According to the survey report, $2 \mathrm{EFL}$ teachers of the public sector focus on GTM to develop their students' accuracy and academic English. In comparison, the other three teachers mainly focus on the CLT approach. However, they also taught grammar content to develop their students' communicative ability and proficiency. Data analysis highlights that these teachers do follow prescriptive Methods: "a grab bag of classroom practices" (Bell, 2003, p.2) but with variations to meet their students' needs, learning goals, and learning style. On the other hand, there are ample evidence of teachers proclivity for "traditional approaches rather than being innovative". In other words, there should be a shift from teacher-centred to learner-centered (Soomoro \& Memon, 2016, p.3).

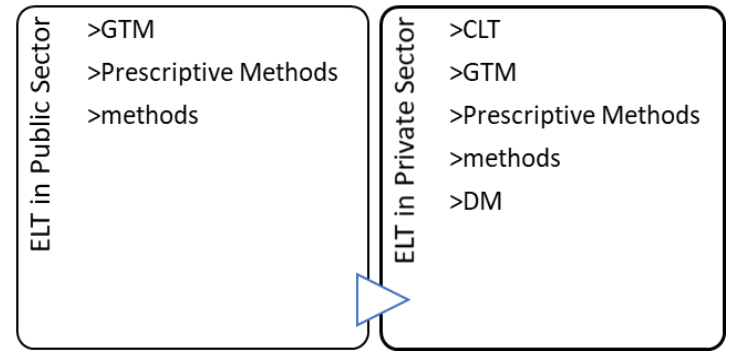

Figure 4.1 ELT in the public and private sector

We should also note here that Pakistan is one of the underdeveloped countries that has not seen notably consistent socio-economic growth since her establishment in 1947. As a result, ELT in the country lacks technological advancement due to which GTM is usually preferred and practised mostly (Zohra \& Abbas, 2018). However, it is recent that the Higher Education Commission (HEC) of Pakistan started a project on English Language Teaching Reforms (ELTR). This project's primary purpose was to bring about some effective change in the ELT profession (Khattak \& Abbasi, 2010).

\section{Discussion}

Method and the Post-method era have recently been the well-debated EFL topics worldwide (Almaktary et al., 2017). Hence, we learn, Bell (2003) discusses the term method with lowercase " $m$ " as "a grab bag of classroom practices" (p.2) that includes. He then cites Oller (1993), "programs, curricula, procedures, demonstration..." (p.2). On the other hand, a method with uppercase $\mathrm{M}$ stands distinctly as "A fixed set of classroom practices that serve as prescription and therefore do not allow variation," (Bell, 2003). The data reveal that in Pakistan, all the participatory teachers use a method, not a method. Like participant C\& D if using GTM in public sectors also use activities, and techniques related to Direct Method (DM) and CLT because of the pressure from education authority in public sectors to make students communicate and get proficiency. The other participants, focusing more on communicative language functions, would do well not to ignore teaching the language's form. Simultaneously, it is also observed that learning another language much depends on Lerner's strategies and techniques (Ali \& Hanan, 2019). In contrast,, citing Kramsch \& Sullivan (1996), Ahmed \& Arif stress the dependency on ELT teachers' global approach while infusing local context informing strategies for language development. 


\subsection{Language and Culture}

English has been learned and used by millions of people worldwide in many settings, including higher educations. Countless people have developed their English language proficiency in public and private educational institutes (Yuzar, 2020). Language teachers in developing countries must develop their pedagogy relevant to their culture and learning styles and their students (Canagarajah, 2002). They seem to resist using the target language's sociolinguistic functions to contain cultural, linguistic norms and behaviours (Kramsch \& Murphy, 1996). This study also analyses English teaching as a foreign language in Pakistan if participants consider the target language's culture as an integral part of L2 or remain intrinsically and eminently 'language' teachers.

Generally, every classroom is also a promising platform associate with the knowledge to learn with the outside worldly experiences (Panhwar et al., 2017). Besides, the text's foreign cultural element is to give language learners information about norms and situated use of language; ultimately, L2 learners understand the language in context. However, partial consideration is given to English's cultural context in Pakistan (Ahmed \& Shah, 2013).

Likewise, Participant A thinks the cultural influence of the target language is inevitable. He seems to remain out of this dilemma and suggests that educational policymakers and curriculum designers consider this problem. Likewise, Participants $\mathrm{C} \& \mathrm{E}$ also seem to think culture is language; they do not underestimate the value of sociolinguistic functions of language and the cultural background of language content. Participant $\mathrm{C}$ believes it is necessary to explain the cultural background of poetry to understand its content. Similarly, participant E views the cultural knowledge necessary to understand the target language fully.

However, participant B \& D do not consider culture as an integral part of the target language, so they seem reluctant to include culture in their language pedagogy.

\subsection{Form or Function/Accuracy or Proficiency}

The English language has the privilege of the official language's status and language of instruction and examination at post-secondary education in Pakistan. In 1976, the first curriculum of English language learning was published in Pakistan. The textbooks help learners achieve the learning objectives described in the Education policy of Pakistan'sPakistan's government (Buriro et al., 2018, p.350). These textbooks are based on GTM and used in the public sectors widely. In comparison, Ahmed \& Rao (2013)believe that the "CLT approach is more suitable for teaching English as a foreign language" (p.8). It is also a growing language of communication especially in the private sectors of business; hence, teachers attempt to train their students to master the formal and functional properties of L2 with practicals knowledge, grammatical accuracy, and communicative appropriacy (Kumaravadivelu, 2006).

This study data reveals that teachers attempt to develop grammatical accuracy through form-based instruction and use meaning-based activities to develop communicative language competence. It also appears that participating teachers in the private sectors blended their learners' learning experiences with visual charts and handouts that could increase interaction between L2 learners and learning material (Yuliana et al., 2020, p.80).

All participants appear to emphasise communicative language teaching, but they do not depend on developing their students' accuracy and English proficiency. Participant A stated that depending on CLT does not give the desired result. Participant E considers communicative ability as the benchmark of language learning. While Participant C, who teaches English in the public sector, seemed to understand the importance of communicative ability but found limited opportunities to conduct meaningbased activities to improve proficiency in the target language. Similarly, participant $\mathrm{C}$ emphasised learning the discrete items of grammatical forms of the English language but did not undervalue understanding language function. To him, language is both: a system of discrete items and a way of expression. Likewise, all participants view language to express meaning but do not devalue learning grammar forms. They all seem to attempt to improve accuracy through form-based instruction and activities and proficiency through meaning-based activities. All participants used supplementary material besides the course books with audio-visual aid to achieve accuracy and proficiency, except participant B who do not follow any sourcebook and develop his material to meet his students' needs, learning style, and background.

\subsection{The Parameter of Practicality}

In practice, Kumaravdivelau stresses that teachers must develop context-sensitive pedagogy according to their students' culture. To see if these teachers do construct their context-sensitive theory of practice or follow the theories developed by western scholars, this study also asked participant teachers about what factors, like age, learning goal, learning style, educational, and economic background. They consider in developing their pedagogic strategies and technique.

The apparent issue with the methods appears in failing to recognise every context of language learning and teaching (Khatum, 2018, p.424). In the same light, the study shows that all participants do not strictly follow Western scholars; instead, they all seem motivated and aware of developing their 
practice theory. What a language teacher does in a classroom may not resemble any specific method, Canagarajah (2002). In the same manner, participant B considers "social, cultural, economic, political and psychological context" in developing teaching strategies and techniques. On the other hand, participants $\mathrm{C}$ exercises these theories as an "umbrella" not to go stray from authentic practice. He believes that these Western scholars "do not reflect the local need" of his students. To develop his theory of practice, Participant $\mathrm{C}$ consider age learning goal, L1 and learning background to construct his contextsensitive pedagogy.

\subsection{To Teach or to Transform}

Pakistan is suffering from political, economic instability due to inequality and injustice. This study investigates if teachers bring their social and political lived experience into the classroom to transform the local setting's social and political reality. The data tells that not all participants are willing or allowed to discuss political and social disturbance. A teacher in the public sector tries to discuss the socio-political realities more than he is allowed to do. Similarly, Participant B \& E consider it teachers' responsibility to transform student's social-political life. However, participant $\mathrm{D}$ does not discuss politics in the classroom at all. The data provide evidence that teachers may play the role of the transformative intellectual in Pakistan if they are willing to do so.

\section{Conclusion}

Language teachers have always sought an 'ideal method" to develop their students' English language proficiency, and that also has some universal application for all L2 learners (Islam, 2020, p.135). Similarly, EFL teachers in Pakistan appear in this study in search of the best method. Therefore, this study focuses on collecting empirical data to analyses teaching methods and strategies being applied by EFL teachers in Pakistan. It provides evidence that teachers in the periphery community are still practising prescriptive methods with variation to harmonise their pedagogy with their students' needs, learning goals, and learning desire. Hence, this study demonstrates that "methods are not dead, nor will they ever be," (Bell, 2003, p.10). The qualitative survey reported that teachers in the public sector tend to apply older strategies and techniques of GTM compared to the teachers in the private sector. The latter attempts to develop their students' communicative ability and proficiency. Public sector teachers mostly aim at developing accuracy by mastering grammatical forms and paying less attention to communicative appropriacy. Contrary to this practice, teachers in the private sector attempt to develop proficiency by mastering meaningful communicative expression and paying less attention to grammatical accuracy.
Soomro et al. (2016) mentioned the 2003 curriculum and textbook reform by the Civil Society of Pakistan that highlighted the complications of EFL textbooks for the students of the public sector and emphasised the unexclusiveness of situated use language in real life. The study also demonstrates that teachers in the public sectors are more constrained and cannot apply methods like Audio-lingual Method, Direct Method, Communicative Language Teaching, or Task-Based Language Learning. Unlike teachers in the private sectors who are free to develop their learning material and adopt techniques and strategies commonly attributed to prescriptive methods. As a result of outdated GTM, students of public sectors face a substantial predicament in communicating in English in real life (Abrejo et al., 2019, p.44). To conclude, this study data provide evidence for a wide gap of research on the EFL teaching method and considerable need to rethink the language educational goal for redesigning language teaching pedagogy in Pakistan.

\section{Acknowledgement}

I would like to acknowledge Professor Jeff Bale of the Ontario Institute for Studies in Education for his valuable guidance and cooperation for this study.

\section{References}

Abrejo, B., Sartaj, S., \& Memon, S. (2019). English Language Teaching through Communicative Approach: A Qualitative Study of Public Sector Colleges of Hyderabad, Sindh. Advances in Language and Literary Studies, 10(5), 43-49.

Ahmad, I., \& Arif, M. S. (2020). Teachers' Perception of English Language Teaching at Tertiary Level Education in Pakistan. Pakistan Social Science Review, 4 (1), 191-203.

Ahmed, M., \& Shah, S. K. (2013). The Relationship in Culture and ELT: The Representation of Aesthetic Sense Culture in "Oxford Progressive English". Journal of Education and Practice, 5(4), 150-158

Ahmad, S., \& Rao, C. (2013). Applying the communicative approach in teaching English as a foreign language: a case study of Pakistan, Porta Linguarum, 20, 187-203.

Akbari, R. (2008). Postmethod discourse and practice. TESOL quarterly, 42(4), 641-652.

Almaktary, H. M. A., \& Al-Kadi, A. M. T. (2017). CALL in Post-Method Era. Indonesian Journal of EFL and Linguistics, 2(2), 133-146.

Asghar, J., \& Butt, M. I. (2018). A Critique of National Curriculum for English Language in Pakistan: Proposing Cognitive Strategy 
Instruction for ELT. Kashmir Journal of Language Research, 21(1), 75-86.

Bell, D. M. (2003). Method and postmethod: Are they really so incompatible? TESOL quarterly, 37(2), 325-336.

Buriro, G. A., Abdullah, M., \& Mehdi, M. (2018). A Critical Analysis of ELT Syllabus at Secondary Level in Pakistan. Grassroots, 51(2), 345-358

Canagarajah, A. S. (2002). Globalisation, methods, and practice in periphery classrooms. Globalisation and language teaching, 134-150.

Ghulamullah, D. M. (2017) Factors Affecting First Language Acquisition. International Journal of English Language, Literature and Translation Studies, 4(2), 481-487

Gulzar, M. A., \& Sultana, N. (2009). Shift in the Language Teaching Methods: Implications of the Methodologies in Pakistani EFL Classrooms. Kashmir Journal of Language Research, 11(1), 121-130.

Islam, N. N. (2020). Implementation of Postmethod Pedagogy as an Alternative to Communicative Language Teaching at the Tertiary Level Education. IJOLTL-TL Indonesian Journal of Language Teaching and Linguistics, 5(3), 135154. DOI: 10.30957/ijotl-tl.v5i3.633.

Warsi, J. (2004). Conditions under which English is taught in Pakistan: An applied linguistic perspective. Sarid Journal, 1(1), 1-9.

Jamil, S. (2014). Critical Perspective in English Language Teaching in Pakistan: the Possibilities. Gomal University Journal of Research, 30(2), 11-18.

Khan, A., \& Akhtar, M. (2017). Investigating the Effectiveness of Cooperative Learning Method on Teaching of English Grammar. Bulletin of Education and Research, 39(1), 1-16.

Khaliq, A., Ali, A., \& Hanan, F. (2019). ELT Teachers' Attitude towards Language Learning Strategies Used in Southern Punjab, Pakistan. Global Regional Review, 4(1), 271-280.

Khan, T. (2016, August 25). English Language Teaching in Pakistan. Retrieved from http://www.dawn.com/news/663605/englishlanguage-teaching-in-pakistan.

Khattak, I \& Abbasi, G. (2010). Teachers' Professional Development in ELT at Tertiary Level: ELTR Project of the Higher Education Commission of Pakistan, 10(6), 153-167

Khatun, M. S. (2018). The Role of EFL/ESL Teachers' Idiosyncratic Knowledge Base in Their Professional Development in the Postmethod
Premise. Journal of Literature and Art Studies, 8(3), 422-436.

Kramsch, C., Cain, A., \& Murphy-Lejeune, E. (1996). Why should language teachers teach culture?. Language, culture and curriculum, 9(1), 99-107.

Kumaravadivelu, B. (2003). Beyond methods: Macrostrategies for language teaching. Yale University Press.

Kumaravadivelu, B. (2006). Understanding language teaching: From method to postmethod. Routledge.

Larsen-Freeman, D., \& Anderson, M. (2000). Techniques and Principles in Language Teaching 3rd edition-Oxford Handbooks for Language Teachers. Oxford university press.

Mitchell, C. B., \& Vidal, K. E. (2001). Weighing the ways of the flow: Twentieth century language instruction. The Modern Language Journal, 85(1), 26-38.

Myles, F. (2010). The development of theories of second language acquisition. Language Teaching, 43(3), 320-332.

Panezai, S. G., \& Channa, L. A. (2017). Pakistani government primary school teachers and the English textbooks of Grades 1-5: A mixed methods teachers'-led evaluation. Cogent Education, 4(1), 1269712.

Panhwar, A. H., Baloch, S., \& Khan, S. (2017). Making communicative language teaching work in Pakistan. International Journal of English Linguistics, 7(3), 226-234.

Soomro, M. A., Memon, N., \&Memonc, S. A. (2016). Concept of Best Practices in English Language Teaching to Pakistani ELT Fraternity. Advances in Language and Literary $\quad$ Studies, 7(4), 119123.

Teevno, R. A. (2017). Challenges in teaching and learning of English at secondary level class $\mathrm{X}$. Pakistan Journal of Language and Linguistics, 1(3), 35-43.

Warsi, J. (2004). Conditions under which English is taught in Pakistan: An applied linguistic perspective. Sarid Journal, 1(1), 1-9.

Yuliana, R., Marwa, M., \& Hamuddin, B. (2020). The Investigation of Students' Knowledge on a Novel Learning Strategy: What is Interesting about Blended Learning for EFL University Students?. Utamax: Journal of Ultimate Research and Trends in Education, 2(2), 80-87.

Yuzar, E. (2020). Incorporating Communicative Competence in Assessment and English Language Teaching in Multilingual Settings. REiLA : Journal of Research and 
Innovation in Language, 2(1), 8-13. DOI: 10.31849/reila.v2i1.3864

Zahra, T., \& Abbas, A. (2018). Pedagogical Implications of Corpus-Based Approaches to ELT in Pakistan. Journal of Education and Educational Development, 5(2), 259-275. 